\title{
Epidemic measles in Shetland during 1977 and 1978
}

\author{
J D MACGREGOR, JILL MACDONALD, E A INGRAM， M MCDONNELL， B MARSHALL
}

\begin{abstract}
During 1977 and 1978 an unusual epidemic of measles occurred in Shetland, affecting $1032(5 \%)$ of the population. All age groups were represented, and 309 cases occurred in people over 15. Geographical distribution of notified cases ranged from $1 \%$ to over one-third of the population aged under 65 . All the recognised complications occurred, with a significant excess of respiratory troubles $(\mathbf{p}<\mathbf{0 . 0 5})$. Complications were much less common in female patients $(p<0.05)$. Only about $30 \%$ of children under 5 had been vaccinated against the disease, and, based on a sample population, vaccination was found to have had a protective effect of $92 \%$.

On cost effectiveness alone, uptake of vaccination by a community as susceptible as that of Shetland should clearly be encouraged and probably given high priority.
\end{abstract}

\section{Introduction}

Vaccination against measles was introduced over a decade ago as a standard component of the nationally recommended vaccination schedule ${ }^{1}$ for infants in Britain. In Scotland, however, the vaccine acceptance rate has seldom exceeded $55 \%$, which is much below the $90 \%$ or so required ${ }^{2}$ to halt transmission of the disease.

During an upsurge of measles in 1977 and 1973 a notable outbreak occurred in Shetland (see fig 2), the most northerly island group in Britain. The epidemic affected people of all ages and in all islands except three of the most remote. Before the epidemic the measles vaccine acceptance rate in Shetland had been around $30 \%$ in the under- $5 \mathrm{~s}$, while few if any of the older children and adults had been vaccinated. Serological surveys ${ }^{3}$ had indicated that a substantial proportion of the adult population in Shetland had no or very low measles antibody titres, reflecting the absence of epidemic conditions since 1963.

A major factor initiating change had been the advent of the North Sea oil industry from about 1974. This stimulated a great increase in population movement to and from the Scottish mainland and, indeed, further afield, and introduced new employment opportunities supplementing the traditional knitting, crofting, and fishing. Moreover, as these events coincided with much improved internal communicerions, based on inter-island vehicle ferries linking all of the larger communities, the potential for rapid transmission of infection was much enhanced. Thus by 1977 Shetland was clearly ripe for a sizable epidemic, but the magnitude of the actual outbreak suggested

Shetland Health Board, Lerwick, Shetland ZE1 OQP J D MACGREGOR, MD, FFCM, chief administrative medical officer JILL MACDONALD, MB, CHB, clinical medical officer

Lerwick, Shetland

E A INGRAM, MB, FRCs, general practitioner

Yell and Fetlar, Shetland

M MCDONNELL, MB, MRCGP, general practitioner

Whalsay and Out-Skerries, Shetland

B MARSHALL, MB, BS, general practitioner that scant attention had been paid to exhortations (JDM, circular letter "Immunisation against measles," 11 March 1976) to improve vaccination rates.

\section{Methods}

Initial monitoring of the spread of measles was done through the medium of the statutory notification procedure, whereby the attending family doctor is required to furnish information on each case of certain infectious diseases to the local health authority. When the scale of the epidemic became clear doctors were also urged to report the nature and severity of any complications which developed in individual cases. This did not prove especially fruitful, however, partly because of the excessive work load under which they were by then labouring and partly because the initial notification had often been made before the complication, if any, had developed. It was therefore later decided to employ a retrospective questionnaire on the lines of that used by Miller $:$ this provided information on a sample basis concerning the clinical severity of and complications in notified cases, some indication of the nature and extent of active treatment given, the duration of the illness, and whether or not hospitalisation had proved necessary. Adequate information was for the most part obtained from the family doctors' records, though it was necessary to supplement this in some cases by interviewing the patient or relatives.

To assess the effectiveness of prior vaccination against measles the records were examined of all 547 children in five rural practices who were under the age of 5 years at the time of the outbreak and whose

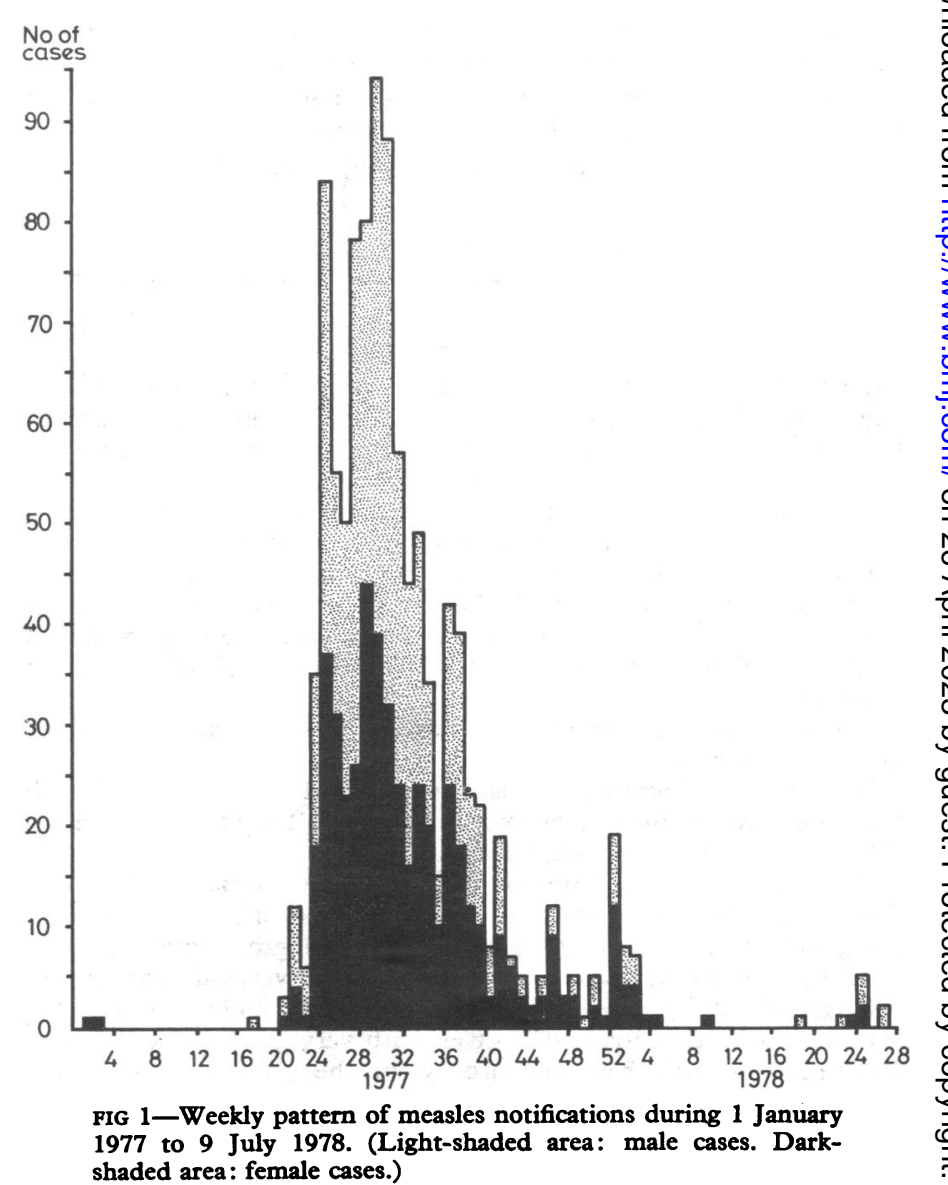


vaccination history was accurately known. Notification rates in the vaccinated and unvaccinated groups were then compared.

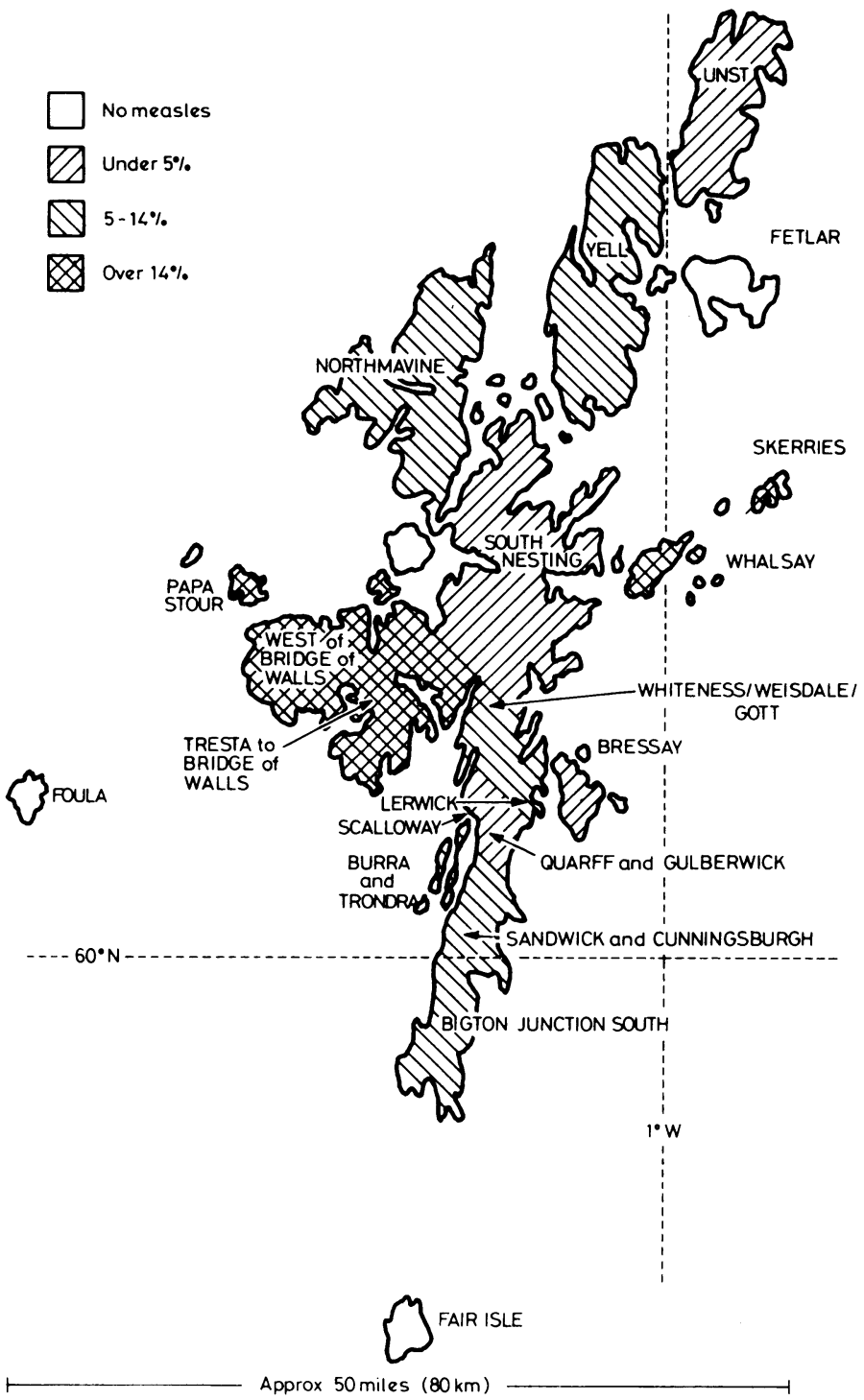

FIG 2-Measles attack rates in under-65s in Shetland Islands.

\section{Results}

Two cases of measles were notified in January 1977, the first being a housebound elderly woman, and the second a 2-year-old girl. They lived some 20 miles $(32 \mathrm{~km})$ apart, and there was no known contact between them. No secondary cases were reported, no laboratory confirmation was available, and these diagnoses must therefore remain unconfirmed. The true index case was apparently a 13-yearold boy, resident two miles from Lerwick, the principal town in Shetland. He had not been out of the islands and had no known contact with persons from the Scottish mainland or elsewhere before his illness, which was diagnosed on 7 May 1977 (week 18). The ensuing two weeks passed with no secondary cases notified, but modest numbers followed in weeks 21 and 22, all from adjacent areas in and around Lerwick and Scalloway (see fig 2).

The disease spread to more rural areas in week 23 , and this was followed by a major upsurge in notifications from most parts of the mainland, followed by the islands of Whalsay, Yell, and Unst in that order. The remote island of Out-Skerries and the most distant rural areas of north mainland were the last to produce cases (during week 29), while the even more distant islands of Fetlar, Foula, and Fair Isle appeared to escape the infection entirely. Papa Stour, an equally remote island, also escaped for several months longer until mid-June 1978, when a brisk outbreak affected eight of the 11 children on the island.

Figure 1 shows the weekly pattern of notifications. The noticeable periodicity, with a fall in the number of notifications in weeks 27,32 , $36,41,45$, and 50 , corresponding to weeks beginning 4 July, 8 August 5 September, 10 October, 7 November, and 12 December, suggested that an accumulation of notifications were completed just after the end of each month.

Of the 1032 cases of measles notified during the epidemic, 309 $(30 \%)$ were in people aged over 15 , with appreciable numbers occurring in all age groups (table I). The male to female ratio was $1 \cdot 31: 1$, with the greatest difference being in young adults, among whom half as many again were male. This was probably due to the need for medical certification by employed youths and possibly to reluctance by affected mothers to seek medical attention for themselves.

From area to area the proportions of the population affected varied widely-from just under $1 \%$ in Bressay Island to over one-third of the population under the age of 65 in Out-Skerries (fig 2). There was a highly significant difference in the proportion of the population notified in the five areas with rates over 140 cases/1000 population as compared with the proportion in the remaining areas $(p<0.001)$.

Retrospective information on complications provided by the family doctors concerned varied from anecdotal, in which some doctors thought that complications were uncommon (but qualified in at leas one instance by the observation that antibiotics were prescribed routinely), to the more detailed results of a questicnnaire. This was applied to all 207 patients notified from two island practices, of whom 111 were male and 96 female. Forty-one of these notified patients

TABLE I-Notifications of measles by age-group, sex, and rates per thousand population

\begin{tabular}{|c|c|c|c|c|c|c|c|c|c|c|c|}
\hline \multirow{2}{*}{ Patients } & \multicolumn{11}{|c|}{ Age group (years) } \\
\hline & $<1$ & $1-4$ & $5-14$ & $15-24$ & $25-34$ & $35-44$ & $45-54$ & $55-64$ & $65-74$ & $>74$ & Total \\
\hline $\begin{array}{l}\text { Males } \\
\text { Females }\end{array}$ & $\begin{array}{r}8 \\
17\end{array}$ & $\begin{array}{l}83 \\
78\end{array}$ & $\begin{array}{l}284 \\
253\end{array}$ & $\begin{array}{r}123 \\
82\end{array}$ & $\begin{array}{l}16 \\
17\end{array}$ & $\begin{array}{l}13 \\
11\end{array}$ & $\begin{array}{l}12 \\
12\end{array}$ & $\begin{array}{l}5 \\
8\end{array}$ & $\begin{array}{l}2 \\
1\end{array}$ & $\begin{array}{l}1 \\
6\end{array}$ & $\begin{array}{l}547 \\
485\end{array}$ \\
\hline Total & 25 & 161 & 537 & 205 & 33 & 24 & 24 & 13 & 3 & 7 & 1032 \\
\hline $\begin{array}{l}\text { Population* } \\
\text { Rate/1000 population }\end{array}$ & & & $\begin{array}{r}3300 \\
163\end{array}$ & $\begin{array}{r}2900 \\
71\end{array}$ & $\begin{array}{r}3200 \\
10\end{array}$ & $\begin{array}{r}2200 \\
11\end{array}$ & $\begin{array}{r}2000 \\
12\end{array}$ & $\begin{array}{r}1900 \\
7\end{array}$ & $\begin{array}{r}1900 \\
2\end{array}$ & $\begin{array}{r}1100 \\
6\end{array}$ & 20200 \\
\hline
\end{tabular}

* Midyear 1977 population data from General Register Office for Scotland.

TABLE II-Complication rates reported by Miller ${ }^{5}$ in England and Wales during 1976 and in Shetland during 1977-8

\begin{tabular}{lccccc}
\hline & \multicolumn{2}{c}{$\begin{array}{c}\text { England and Wales } \\
\text { Cof measles cases = 8978) }\end{array}$} & & \multicolumn{2}{c}{$\begin{array}{c}\text { Shetland } \\
\text { (No of measles cases = 207) }\end{array}$} \\
\cline { 2 - 3 } & $\begin{array}{c}\text { No with } \\
\text { complications }\end{array}$ & $\%$ & & $\begin{array}{c}\text { No with } \\
\text { complications }\end{array}$ & $\%$ \\
\hline Respiratory & 403 & $4 \cdot 49$ & & 15 & $7 \cdot 25$ \\
Neeurological & 62 & $0 \cdot 69$ & & 2 & 0.97 \\
Otitis media & 461 & $5 \cdot 13$ & & 6 & $2 \cdot 90$
\end{tabular}

Statistical data (with Yates's correction)-Respiratory, $\chi^{2}=2.936 ; p<0.05$. NeuroStatistical data (with Yates's correction - Respiratory,
logical, $\chi^{2}=0.002 ;$ NS. Otitis media, $\chi^{2}=1.659 ;$ NS.
$(20 \%)$ were considered by their doctors to have been moderately or severely ill, and the proportion increased noticeably with age. Furthermore, a greater proportion of the over-25s than younger age groups were unwell for 15 days or more ( $\chi^{2}$ test at $1 \mathrm{df}=14.994 ; \mathrm{p}<0.001$ ). Of the 41 patients, 27 (20 male) had complications: bronchitis and otitis media (15 and six cases respectively) affected principally the younger age groups, while two cases of encephalitis occurred in patients aged 15 and 64 . The relative freedom of female patients from complications was significant $\left(\chi^{2}\right.$ test at $\left.1 \mathrm{df}=4.319 ; \mathrm{p}<0.05\right)$. Table II compares the overall complication rates with those reported by Miller $^{5}$ in the larger, 1976 series in England and Wales. The difference 
in respiratory complication rates was only just significant at the 5\% level. Other differences did not reach statistical significance.

Analysis of the records of 547 children aged under 5 at the time of the outbreak showed that 146 had been vaccinated against measles and 401 had not. Of these, $2(1 \cdot 4 \%)$ and $70(17 \cdot 5 \%)$ respectively contracted the disease.

\section{Discussion}

Island communities have historically suffered considerably from the depredations of measles. In 1846 an epidemic in the Faröes $^{6}$ was very severe, with three-quarters of the population affected and a resultant mortality of about $2 \%$; another in Fiji in 1875 was even more devastating, with an overall mortality of about $25 \%{ }^{7}$ Similar epidemic conditions have been described more recently in virgin populations in New Guinea, ${ }^{8}$ but an explosive type of epidemic rarely occurs in more developed countries.

The Shetland epidemic was unusual in several respects. Unlike most northern hemisphere measles outbreaks, which occur in winter and spring, ${ }^{9}$ it began in early summer and reached its peak in July and August. This was fortunate only for education, as most schoolchildren were on holiday when they contracted the disease. Secondly, although the epidemic was initially confined to the younger age groups, it rapidly spread to adults. Indeed, $30 \%$ of all cases were in people over 15 years of age, with appreciable numbers in all age groups. The two oldest patients notified were 84 , while the youngest was only 8 weeks. In contrast, less than $2 \%$ of patients were over 15 in the 1976 measles epidemic in the Bahamas ${ }^{10}$; while in Scotland generally the disease is most prevalent in the 1-4-year age group, but with a notification rate of only $13 / 1000$ population in that age group in 1977.11

The pronounced variation both in the geographical distribution of notified cases and in the duration of the epidemic in the different areas may in part be attributed to a relative enthusiasm of notifying physicians but is more likely to have been due to such factors as past exposure to measles, varying opportunities for transmission, the degree of population movement, and changing attitudes to infectious disease. For example, there is no record that either Whalsay or Out-Skerries was affected during the 1963 measles outbreak, which was "fairly prevalent throughout the mainland of Shetland," 4 and these communities must therefore have been very vulnerable to infection by 1977 . Yet in sharp contrast to the quarantine that would have been selfimposed a generation before in rural Shetland, virtually the entire population attended weddings in these two islands despite the presence of measles. Actual cases seen at these gatherings must surely have contributed greatly to the high rates of infection.

Though some doctors considered that complications were uncommon, detailed study of patients notified from two practices showed that, in these patients at least, all the recognised complications occurred, including encephalitis, otitis media, and acute bronchitis. As in the United States, where the incidence of measles encephalitis is directly related to age, ${ }^{12}$ the neurological complications occurred in older patients. About one in five of the patients were considered by their family doctor to have been either moderately or severely ill. A substantial proportion of older patients were unwell for 15 days or longer; and complication rates were certainly no less than those reported in other British surveys. ${ }^{5}$ In contrast to 1963 in England and Wales, ${ }^{13}$ however, complications in Shetland were notably more frequent in male than female patients. Four patients were known to have been admitted to hospital, and measles caused the death of one patient already severely debilitated by chronic illness.

Measles in Shetland during 1977 and 1978 clearly caused a good deal of morbidity. That the disease may also have been responsible for much absence from work was suggested by the DHSS weekly sickness benefit claim returns: these peaked in week 29 at 97 claims (see fig 1), which is double the normal average for the time of year.

The effectiveness of measles vaccine was confirmed: only two out of 146 vaccinated children under 5 contracted the disease $(1.4 \%)$ compared with 70 out of $401(17.5 \%)$ who had not been vaccinated. Based on these data the protective effect of the vaccine was $92 \cdot 2 \%$ (95\% confidence limits: $85 \cdot 7-98 \cdot 6 \%$ ), which was closely similar to the findings in other series ${ }^{14}{ }^{15}$; and the relative risk of contracting measles if unvaccinated was 12.7 times greater than if vaccinated.

Costs to the Health Service proved difficult to compute from actual payment records; these were therefore estimated on the assumption (based on actual data from one practice) that $30 \%$ of patients were visited at home and that the same proportion were given a prescription. Using average milage payments and prescription costs, we calculate the total cost of these two items alone as $£ 1046$ (1977 prices). On cost effectiveness alone vaccination uptake should therefore be encouraged and, indeed, should probably be given high priority in a community as susceptible as Shetland's proved to be in this epidemic. With hindsight, the comparatively slow spread of the outbreak would have given an opportunity to vaccinate some of the population at risk; Ruuskanen et $a^{16}$ showed that this may be successful even after exposure.

In those persons infected with measles virus the risk of developing subsequent subacute sclerosing panencephalitis may be calculated, on the basis of North American experience, ${ }^{12}$ as around 13:1 against the possibility of one case occurring in Shetland. Nevertheless, these are not particularly long odds against a condition which is invariably fatal and should give further encouragement to vaccination.

We thank Mr D Eva, treasurer, Shetland Health Board, for information on costs, and Mrs M Ewart for typing the manuscript.

\section{References}

1 Department of Health and Social Security, Scottish Home and Health Department, and Welsh Office. Immunisation against infectious disease. London: HMSO, 1972.

2 Sutherland J, Fayers PM. Effect of measles vaccination on incidence of measles in the community. $\mathrm{Br} M e d \mathcal{F} 1971 ; \mathrm{i}: 698$.

${ }^{3}$ Poskanzer DC, Sever JL, Sheridan JL, Prenney LB. Multiple sclerosis in the Orkney and Shetland Islands. IV. Viral antibody titres and viral infections. F Epidemiol Community Health 1980;34:258-64.

${ }^{4}$ Medical Officer of Health for the County of Zetland. Report to Scottish Home and Health Department, County Council of Zetland, and Town Council of Lerwick. Lerwick: Public Health Office, 1964.

5 Miller CL. Severity of notified measles. Br Med f 1978;i:1253.

6 Panum PL. Observations made during the epidemic of measles on the Faroe Islands in the year 1846. Bibliothek for Laeger (Copenhagen) $1847 ; 3 R, 1: 270-344$. (Transl Hatcher AS, US Public Health Service.) Paul H. The control of diseases. Edinburgh: Livingstone, 1964.

8 Adels BR, Gadjusek DC. Survey of measles patterns in New Guinea, Micronesia and Australia. American fournal of Hygiene 1963;77:317.

${ }^{9}$ Rhodes AJ, Rooyen FE. Quoted by Paul. ${ }^{7}$

10 CAREC. Surveillance report. Vol 3. No 2. Feb 1977.

11 Scottish Home and Health Department. Scottish health statistics 1977. Edinburgh: HMSO, 1978.

12 Communicable Diseases Control Unit. Measles surveillance report No 10 1973-1976. DHEW publication (CDC) 77-8253.

13 Miller DL. Frequency of complications of measles, 1963. Br Med F 1964; ii:75-8.

14 MRC Measles Vaccination Committee. Report. Practitioner 1971 ;206:458.

15 Measles Sub-Committee of the Committee on Development of Vaccines and Immunisation Procedures. Fourth report to the Medical Research Council. Lancet 1977;ii:571-5.

${ }^{16}$ Ruuskanen O, Salmi TT, Halonen P. Measles vaccination after exposure to natural measles. F Pediatr 1978;93:43-6.

(Accepted 7 November 1980) 